\title{
The Search for Sweet Georgia Brown: A Case of Discographical Detection
} By

\author{
Peter Ingham and Toru Mitsui
}

In April 1961 The Beatles made their second trip to Hamburg, West Germany, to play a three-month engagement at the Top Ten Club. At this time the group comprised five members-John Lennon (rhythm guitar), Paul McCartney (rhythm guitar), George Harrison (lead guitar), Stuart Sutcliffe (bass guitar) and Pete Best (drums).

During this period the group frequently played with another English musician, Tony Sheridan, whose special talent was his ability to render a passable imitation of the singing style of Elvis Presley. "I was playing at the Top Ten Club on the Reeperbahn. I was without a band at that time, and so we got together. They backed me in my solo numbers, and I played guitar with them when they did their spots" (Sheridan). It was during one or more of such sessions that they were seen by Bert Kaempfert of Polydor Records, who arranged to record Sheridan with backing by The Beatles.

This much is generally agreed by biographers and discographers alike, but it is when it comes to details of the Polydor recording sessions that confusion arises. Different sources report different dates, different group line-ups and different lists of the songs recorded. The task for the discographer, then, is to sift the different reports and to reconcile them with each other and with the internal evidence presented by the recordings themselves.

The problem of which songs were recorded by The Beatles and Sheridan is compounded by the fact that the producer, Kaempfert, decided that the name "Beatles" was unsuitable, supposedly because German pronunciation of the word would be too close to Hamburg slang for male genitalia (Best and Doncaster, p. 107). Instead he christened the group "The Beat Brothers", a name which was thereafter used as a catch-all title for any and all groups of musicians who backed Sheridan on later recording sessions. The result is that Polydor Records possesses and has released a large number of songs recorded by Tony Sheridan and the Beat Brothers, only a few of which feature The Beatles. Those on which The Beatles play are credited to the Beatles or to "Tony Sheridan with The Beatles" (or to "The Beatles with Tony 
Sheridan"). Many people, however, remain under the impression that any recording credited to the Beat Brothers is in reality by The Beatles, an impression that Polydor K.K. Japan at least has been careful not to dispel( ${ }^{*}$.

The only songs which Polydor Records of West Germany has claimed to have been recorded by The Beatles are "Ain't She Sweet" (lead vocal by John Lennon) and "Cry For A Shadow", an instrumental number, and by The Beatles with Sheridan, "My Bonnie", "The Saints (When The Saints Go Marching In)", "Why", "Nobody's Child", "Sweet Georgia Brown", and "If You Love Me, Baby" (also known as "Take Out Some Insurance On Me, Baby").

Other sources add "Skinny Minny" (Best and Doncaster, p. 107), "Some Other Guy", "Rock And Roll Music" (Guzek, p. 2), "Tell Me If You Can", "Kansas City", and "Hey Hey Hey Hey" (Schultheiss, p. 21). Of these titles, Polydor has released a version of "Skinny Minny" (on Beatles Oldies, Polydor 38MM 0109-10, released on 1/ 12/81) and "Kansas City" (on Beatles Oldies, and First, compact disc, Polydor P33P 50012 , released on 1/4/85). Both are credited to Tony Sheridan and the Beat Brothers, i.e. not The Beatles( $*$ ).

It seems reasonable to suppose that if any songs other than those which the record company has claimed were indeed recorded by The Beatles with Sheridan the company would have released them instead of filling out their Beatles releases with a miscellany of songs recorded with other combinations of "Beat Brothers". The fact that Best, The Beatles' drummer, mentions "Skinny Minny" (and incidentally omits any mention of "Nobody's Child") is problematic although it is possible that on this detail his

[ The notes on the "obi" (a paper sash around the sleeve of a record with song listing and notes) of Polydor's Beatles Oldies (38MM 0109/10) read in translation: "This LP is a must for Beatles' fans, and includes 8 SONGS NEVER BEFORE RELEASED IN JAPAN which The Beatles-John Lennon, Paul McCartney,George Harrison and Pete Best-recorded as Tony Sheridan's backing group under the name of 'The Beat Brothers'! This LP, packed with Rock ' $n$ ' Roll numbers, offers an invaluable, indispensable insight into The Beatles' roots!!" In fact, none of the "newly released" songs on this record, as listed on the "obi", is by The Beatles, and two of them ("Kansas City" and "Swanee River") had already been released by Polydor in Japan in the 1960s.]

[ * It should be noted that in 1964 Polydor K.K. Japan released a single of "Kansas City/What'd I Say" (Polydor DP-1429) credited to "The Beatles with Tony Sheridan", presumably under the common misapprehension that all recordings by Tony Sheridan and the Beat Brothers were in fact by Tony Sheridan and The Beatles. The company repeated this error in 1965 when it released a sampler LP entitled $R \& B \quad 65$ (Polydor SLMP-1257) which contained "Kansas City" once again credited to "The Beatles with Tony Sheridan".] 
memory is playing him false $\left({ }^{*}\right)$.

In a 1982 interview (Tamarkin) Best did not mention "Skinny Minny" but, when asked if any of the material from the Polydor sessions remained unreleased, stated, "As far as I know, it has pretty much been uncovered". The record company, with access to the original recording sheets, must remain the most credible source. It therefore seems most likely that The Beatles played only on the eight recordings which the company has acknowledged. This is confirmed by Mr. Horst Hohenboeken, the senior product manager of the International Pop Division of Polydor in West Germany, "We can.... . definitely confirm that no other Beatles recordings are existing [sic] in our files, otherwise they would have been included in the CD" (Letter to the present writers, 21st April, 1986).

The questions of the precise recording dates and the line-up of the group at the time of recording are interconnected. At some time during The Beatles' stay in Hamburg the group's bass guitarist, Stuart Sutcliffe, left the group and it has long been a vexing issue whether the recording sessions took place while he was still a member of the group and whether or not he played on the recordings.

In 1959 Stuart Sutcliffe, an art school friend of John Lennon, had been invited to join the group more because of his looks, his romantic attachment to the idea of a "beat group" and his friendship with John Lennon than for any musical talent. Indeed he could play no musical instrument at the time (Norman, p. 53 ; Davies, p. 59). He was persuaded to use the money he had received for the sale of a painting submitted to the John Moores Exhibition in Liverpool to buy a Hofner President electric bass guitar (Norman, p. 57 ; Brown and Gaines, pp. 32-33; Taylor, pp. 95-96). One of the best photographs of Sutcliffe holding this guitar appears in Vollmer's book of photographs, Rock ' $n$ ' Roll Times (p. 20). The West German firm of Hofner was well known in the U. K. at that time for producing economical replicas of famous American guitars (Lawrenson, p. 161). Indeed, when he could eventually afford to buy his own bass guitar, Paul McCartney chose a Hofner "violin" bass, which became something of a Beatles' trademark.

\footnotetext{
[*In a review, unfortunately anonymous, of Best and Doncaster's book in Record Collector, No.68 (April, 1985), the reviewer notes: "Unfortunately the ravages of time have taken their toll on Best's memory, as they do on us all, and there are very few stories indeed in this book which aren't familiar elsewhere. There are also a number of factual errors-the songs The Beatles recorded with Tony Sheridan, etc.-which suggests that it was other reference sources, at fault themselves, to which Best has been forced to turn."]
} 
Tutored by Lennon and the other members of the group, Sutcliffe became the group's bassist despite his musical shortcomings. However, by the time the group reached Hamburg in 1961, Paul McCartney had become impatient with Sutcliffe's musical incompetence-something which Sutcliffe himself readily acknowledged-and wanted to take over the bassist's role himself (Norman, pp. 105-106). Sutcliffe enrolled in Eduardo Paolozzi's Master Class at Hamburg's State Art School and in June decided to remain in Hamburg and marry a German girl, Astrid Kirchherr (Norman, p.108; Davies, p.104 ; Schultheiss, p. 21 ; Castleman \& Podrazik-B, p. 10 ; Brown and Gaines, p. 52). He left the Beatles quite amicably $\left({ }^{*}\right)$, and Paul McCartney took over the bass guitar (Gambaccini, p. 14; Davies, p. 104 ; Norman, p. 106). Sutcliffe died in Hamburg of a cerebral haemorrhage on 10th April 1962 (Harry, p. 34).

Did Sutcliffe play on the Polydor recordings or not? The external evidence is contradictory. In his sleeve notes Tony Sheridan states: "There were five Beatles in those days: John Lennon, George Harrison, Paul McCartney, Pete Best (who was later replaced by Ringo Starr), and Stuart Sutcliffe .... Those were the original Beatles to be heard on this disc" (Sheridan). The Beatles discographer Neville Stannard writes: "At the time of recording there were five Beatles: John, Paul and George plus Pete Best on drums and Stu Sutcliffe on bass" (Stannard, p. 199), though whether this means that all five actually played on the recording is, perhaps deliberately, left open to question. Guzek (p.2) credits the recordings to John Lennon, Paul McCartney, George Harrison, Stuart Sutcliffe and Pete Best.

On the other hand, Russell (p. 5) says: "The line-up for these recordings was John Lennon, Paul McCartney, George Harrison and Pete Best (Stuart Sutcliffe having left the group to study art)." Peter Doggett, in an article entitled "The Beatles In Hamburg", contends : "Stu Sutcliffe was still a member of The Beatles then, but it is questionable whether his bass-playing would have been good enough for a record.... It seems more likely that Paul played bass" (Doggett). Castleman \& Podrazik, in All Together Now, the first volume of their exhaustive discography of The Beatles, mention only that Pete Best plays drums on the recordings and make no mention of Sutcliffe (Castleman \& Podrazik-A, pp. 157-166). In the second volume, The Beatles Again?, they state that Sutcliffe attended the sessions but did not play (Castleman \& Podrazik-B, p. 10). Reinhart (p. 16) maintains, "Sutcliffe, though still officially with 
the group, was not at these sessions."

In his The Beatles: A Musical Evolution, a revised version of his Ph.D. dissertation in Music, the American musicologist, Terence O'Grady, assumes that Sutcliffe played on the sessions, but clearly has his doubts in the face of the aural evidence of the recordings themselves when he describes the bass playing on "My Bonnie" as being "of remarkable virtuosity considering bassist Stu Sutcliffe's reputation as a weak player" (O'Grady-B, p. 14).

As for the date of the recordings, Stannard (p. 199), Guzek (p. 2), Doggett, and Castleman \& Podrazik (A, pp. 11-12) all give the date of the recordings as May 1961. Russell gives no date for the recording but says that a single of "My Bonnie/The Saints" (Polydor 24 673) was released in Germany in June 1961 (Russell, p. 5). Castleman \& Podrazik also give the same date for the single (A, p. 11), but the possibility exists that Russell used Castleman \& Podrazik as his source for this information. Schultheiss concurs with the May recording date and the June release of the single (p. 21). He notes, however, that Erik Bakker's Beatles Unlimited magazine gives the recording date as April, as does Tremlett (p. 117). Schultheiss, it should be noted, is the supervising editor of the Castleman \& Podrazik discography and presumably relied heavily on their work in the compilation of his own book.

Clearly, if the recording sessions were in May, and if Sutcliffe was still a member of the group, he would have been present at the sessions.

The bass playing on the recordings, however, is competent, though not outstanding, and certainly does not contrast unfavourably with the musical competence of the other members of the group. As we have seen, O'Grady remarks on the discrepancy between the skill of the bass player and Sutcliffe's reputation. On the June $22 \mathrm{nd} / 23 \mathrm{rd}$ session (this probable date for the session is discussed below) a fretted electric bass guitar was used on all the recordings and the playing on every track, with the exception of the instrumental, "Cry For A Shadow", betrays a degree of skill, particularly in the use of runs, and a confident metrical accuracy, neither of which is consistent with Sutcliffe's reported habit of turning his back to the audience to disguise the inadequacy of his fingering. The rather monotonous bass line employed in "Cry For A Shadow" might very well be a deliberate arrangement to highlight the showy guitar playing of George Harrison. Clearly the internal evidence seems to eliminate the possibility of Sutcliffe's participation in the session.

This is presumably the basis of Doggett's contention, and Castleman's and 
Podrazik's similar explanation, that, although a member of The Beatles, Sutcliffe did not play. Castleman \& Podrazik state this as fact although they cite no source for their account. It is simpler to posit that Sutcliffe had already left the group by the time the recordings were made.

On this secondary question of exactly when Sutcliffe officially left The Beatles, there is little specific information. Castleman \& Podrazik (B, p. 10) and Schultheiss (p. 21) give the date as June 1961. Stannard and Doggett both agree that Sutcliffe was still one of The Beatles at the time of the recording sessions so presumably they would date his departure as May or June. Russell states that he left before the recording sessions as do Davies (p. 104) and Norman (pp. 106-107), although none of them gives a date. Williams and Marshall (pp. 185-186) say that it was after Sutcliffe left the group that he wrote a letter on the group's behalf, explaining that they had no intention of paying Allan Williams his commission for finding the group work at the Top Ten Club. Williams reply, which is reproduced in the book, is dated April 20th. A photograph of the original letter appears in Collecting The Beatles by Barbara Fenick (pp. 238-239).

Thus Williams' and Marshall's account puts Sutcliffe's departure before 20th April, a matter of about two weeks after The Beatles' arrival in Hamburg. Russell's and Davies' versions would place it not later than sometime in May, if the recording sessions occurred in May. Norman's account is even less clear. He says that it was a month after Sutcliffe had enrolled in Paolozzi's Master Class that the strain of playing with The Beatles at night, painting in the early hours and attending art school during the day finally forced Sutcliffe to leave the group. Assuming that it would take some time for Sutcliffe to hear about and decide to enroll in Paolozzi's art class and allowing for enrollment procedures, and assuming that a further month passed before he decided to leave the group, his departure would have taken place between mid-May and mid-June. However, Norman also recounts Williams' and Marshall's tale of Sutcliffe being deputed to write the (April) letter to Williams conveying the decision not to pay him a commission. Norman states that Sutcliffe did this "Though... a Beatle no longer" (Norman, pp. 106-107). Brown and Gaines are less clear, saying that Sutcliffe undertook the task "Since he wouldn't be with them any longer to take the blame". This implies that Sutcliffe was still a Beatle, but knew that he would not be returning to Liverpool (Brown and Gaines, p. 52).

If Sutcliffe had left the group before the recording sessions as Russell, Davies and 
Norman suggest, then there can be no question but that Paul McCartney plays the bass on the Polydor recordings. Pete Best's first hand account, published in 1985, suggests that this is indeed what happened. "It had already been decided among the rest of us that he [Sutcliffe] would not take part in the recording session because, it was agreed, the more experienced Paul would make a better showing on bass guitar. I believe Stu had guessed that this might happen, and the embarrassment of having to tell him never arose. Instead he broke the news to us that he wanted to leave..." (Best and Doncaster, p. 106). Best identifies the date of the first of two recording sessions as "around the end of May" (Best and Doncaster, p. 105). Best's version, therefore, places Sutcliffe's departure from the group in late May.

The weight of the evidence, most particularly that of Best and the two biographers, Davies and Norman, points to Sutcliffe's having left the group before the recording sessions. Russell agrees and even those who believe that Sutcliffe was still a Beatle at the time either assume that he did not play (Doggett, Castleman \& Podrazik) or cautiously hedge their bets (Stannard) or admit the dilemma without attempting to solve it ( $\mathrm{O}^{\prime} \mathrm{Grady}$ ). As we have seen, the internal evidence of the recordings also supports the idea that Sutcliffe did not play. Only Guzek and Sheridan himself unequivocally maintain that Sutcliffe played at the sessions.

However, the evidence still leaves the precise date of the recording sessions unclear. If we agree that Sutcliffe left the group before the sessions and if a precise date could be placed on Sutcliffe's departure, then a tentative date could be placed on the recording sessions. Conversely a reliable and precise recording date might help in establishing a date for Sutcliffe's departure.

New light was shed on the question with the release on 1st April 1985 of the Compact Disc (CD), The Beatles-First, the sleeve of which gives details of the recordings "taken from the original recording sheets". These details include the names of the studios where the recordings were made, the names of the engineers and, most importantly as concerns the present discussion, the dates of recording $\left({ }^{*}\right)$. Unfortunately, the recording sheets do not offer any information on the musicians who played on the sessions. Mr. Hohenboeken explained in the letter cited above, "We practically have $[$ sic] no library of documentation of such old recordings. Regarding

[*It should be noted that the cover pictures show a Beatles line-up including Ringo Starr. Starr did not join The Beatles until more than a year after the recordings were made. Could this be a deliberate deception, the results of carelessness or an April Fool's joke?] 
the recording sheets, they just mention what is printed in the booklet [i.e. the CD sleeve] , but not additional info like musicians' names."

On the face of it, this objective record must be considered more reliable than information from other sources. Even Best's eye-witness account is not totally reliable, as we have seen, and by his own account this period of The Beatles' life was hectic and wild, and time may have dimmed his memory for precise facts.

The recording sheets date the sessions as taking place on 22nd and 23rd June ("Ain't She Sweet", "Cry For A Shadow", "The Saints", "My Bonnie", and "Nobody's Child") at the Friedrich Ebert Halle, Hamburg-Harburg, and on 24th June ("If You Love Me, Baby") at Studio Rahlstedt, Hamburg. The date and location given for the recording of "Sweet Georgia Brown" is 21st December at Hamburg Musikhalle. (This discrepancy is discussed below.) In both the 1982 interview (Tamarkin) and in his book (p. 106), Best speaks of the first session at a "School hall" (in German "Halle"), and a second session "later" at a "studio" (Studio Rahlstedt?) at which "Sweet Georgia Brown' and all that" was recorded. Best's account seems to corroborate the recording sheets' evidence of two sessions and the locations.

Doggett agrees that there were two sessions but places them a week apart. He agrees that the first session produced "My Bonnie", "Why", "The Saints" and "Cry For a Shadow", but maintains that "Ain't She Sweet" and "Nobody's Child" were recorded at the second session with "If You Love Me, Baby" and "Sweet Georgia Brown". Russell concurs with Doggett, although his account seems to place the second session several months later $\left(^{*}\right)$.

Other sources disagree. At the very least, they say that the two Beatles' numbers, "Ain't She Sweet" and "Cry For A Shadow", were recorded at a single session (Best and Doncaster, p. 107 ; Davies, pp. 103-104 ; Norman, p. 107). As for Russell's apparent dating of the second session after September, Davies (p. 134), Norman (p. 140), Best (p.

["“The first release from this session was a single, 'My Bonnie/The Saints', which was released in Germany on Polydor 24673 in June. The record sold extremely well and The Beatles were soon in the German Top Ten. In September of 1961, after the success of the single, Polydor put together an EP containing 'My Bonnie', 'Why (Can't You Love Me Again)', 'Cry For A Shadow' and 'The Saints'. Although this didn't sell as well as the single, The Beatles had a second recording session with Polydor at which they recorded 'Ain't She Sweet', 'Take Out Some Insurance On Me, Baby', 'Sweet Georgia Brown' and 'Nobody's Child" "(Russell, p. 5). Russell is the only source, incidentally, to suggest that the 'My Bonnie' single was a sizable hit in Germany. Best says more modestly that "It did reasonably well" (Best and Doncaster, p. 107).] 
149) and, less certainly, Schultheiss (*) rule out the possibility. The Beatles did not return to Hamburg until April 1962.

If one assumes that dates and information on the recording sheets are correct, then the conflict between the time of Sutcliffe's departure and the internal evidence of the music, which indicates a bassist of comparable musical competence with the rest of the group, is resolved. If Best is about four weeks out in his estimate of the date, then his account of Sutcliffe's leaving shortly before the sessions squares with Schultheiss' and Castleman's and Podrazik's accounts which state that Sutcliffe left the group in June. His impending marriage might well have provided a pretext.

It seems probable therefore that the sessions took place on 22nd, 23rd and 24th June 1961 with a group which comprised John Lennon (rhythm guitar), Paul McCartney (bass guitar), George Harrison (lead guitar) and Pete Best (drums), and that Tony Sheridan's sleeve notes, mentioned above, refer to the line-up of the group with which he played at the Top Ten Club but not to the line-up with which he recorded. The only discrepancy left is the date of the release of the "My Bonnie" single, which, as detailed above, Russell and Castleman \& Podrazik place in June. Best says that The Beatles returned to Liverpool in "June or July '61" with the single (Tamarkin). This might have been an advance copy given to the group. Conceivably the record could have appeared within a week of recording. Although possible to reconcile with the June 22 nd -24 th recording dates, the June release date of the single casts a minor doubt on the accuracy of the $\mathrm{CD}$ sleeve notes.

The conclusion above is probable, however, only if the CD sleeve is to be believed. As we have seen there is at least one discrepancy that provides room for doubt.

Of course, the recording sheets provide the most accurate and objective record and might be considered the last word on the matter were it not for the one major question which arises over the recording date of "Sweet Georgia Brown". The recording sheets as reported on the $\mathrm{CD}$ sleeve say that the song was recorded by "The Beatles with Tony Sheridan" on 21st December 1961 at Hamburg Musikhalle.

No-one disputes the fact that The Beatles recorded a version of this song with

[* "1962-January-The Star Club opens in Hamburg, Germany, with The Beatles as first-nighters ; they stay for only a few weeks, returning in April." No other source suggests that the Star Club opened before April. Schultheiss's more detailed chronology of the period also reveals no available "few weeks" for this to have happened (Schultheiss, pp. 28-31).] 
Sheridan (*). Best mentions the fact in both his book (p. 107) and the 1982 interview (Tamarkin), but says that the recording was made at the second "later" session in a studio, presumably the 24th June session at Studio Rahlstedt. "Sweet Georgia Brown" is one of the eight songs that Polydor has touted relentlessly since 1964 as its contribution to The Beatles' oeuvre.

However, in December 1961 The Beatles were performing in and around Liverpool (Schultheiss, pp. 25-26) and so could not have recorded in Hamburg at that time. If the $C D$ sleeve notes can be so wildly wrong about this recording, then clearly they cannot be relied on when it comes to the others.

The clue to a possible explanation lies in the fact that another song, called "Ready Teddy", was recorded at the same session by "Tony Sheridan and the Beat Brothers", i. e. not The Beatles. Why would two groups be booked for the same session? Is it possible that Tony Sheridan recorded the song twice, once in June 1961 with The Beatles, and again in December with another group of "Beat Brothers"? As it happens there are indeed two versions of "Sweet Georgia Brown" extant on Japanese record releases, although both are credited to The Beatles with Sheridan.

The version of the song which appears on the $C D$ is the version which has been released all over the world as being by The Beatles and Sheridan. This also appears on Beatles Oldies. For convenience we shall refer to this version as "Version A". Clearly the $\mathrm{CD}$ sleeve notes do not refer to this recording, unless one accepts the extremely improbable thesis that Polydor has been guilty of massive, global fraud.

The other version, which we shall call "Version B", appears on the Japanese LP, In The Beginning(1961) (Polydor MP-2326, released on 21/9/73, later reissued as The Beatles 1961, Polydor MPF-1024, on 21/9/79).

"Sweet Georgia Brown" commends itself to the discographer's attention for two reasons. Firstly, it is the only one of The Beatles' Polydor recordings on which a piano appears. This is presumably played by Paul McCartney (Stannard, p. 199; O'Grady-B, pp. 14-15). Best informs us that McCartney used to play the piano when

\footnotetext{
[ ${ }^{*}$ It is interesting to note that O'Grady in his original Ph.D. dissertation states quite categorically that " 'Sweet Georgia Brown', attributed to 'The Beatles', also lacks authentic Beatle accompaniment. This recording features a commercial style of accompaniment quite unlike The Beatles' usual style" (O'Grady-A, p. 38). However, for reasons which are not explained, in the revised version published as The Beatles: A Musical Evolution, he has abandoned this contention and speaks confidently of The Beatles' accompaniment to "Sweet Georgia Brown" (O'Grady-B, p. 14).]
} 
The Beatles backed Sheridan at the Top Ten Club (Best and Doncaster, p. 103) (*).

Secondly, the recording has a curious history. Although recorded in 1961 and released in Germany in October 1962 on an EP called $Y a-Y a$ (Polydor 21485) by Tony Sheridan and the Beat Brothers, it remained unreleased elsewhere until 31st January 1964 when it was issued as a single, "Sweet Georgia Brown/Nobody's Child" (Polydor NH 52-906), in Britain, to cash in on The Beatles' fame. In the meantime it had undergone a transformation. In the summer of 1963 (Doggett), Sheridan had rerecorded the vocal track to include references to The Beatles, presumably to increase the song's appeal. The final eight bars of the thirty-two bars of the first verse were changed to read:

In Liverpool she even dared
To criticize The Beatles' hair
With their whole fan club standing there
I mean Sweet Georgia Brown

(Note: The complete lyrics to the original 1925 version, Version A and Version B are given in the appendix.)

The original version, without these changes and which we shall refer to as "Version $\mathrm{A}^{\prime}$ ", has reportedly reappeared since only on a limited edition EP issued in Sweden in late $1982(*)$.

Three questions beg an answer. Could it be that Version B is the same as Version $\mathrm{A}^{\prime}$ ? Is Version $\mathrm{B}$ an alternate recording from the June 24 th session with the Beatles providing the musical backing? Or is Version $B$ a separate recording made at the 21st December session with a different group of "Beat Brothers", the same group as that which recorded "Ready Teddy" on that date? If the latter, then presumably the CD sleeve notes are accurate, although they refer to a quite different recording to Version A which actually appears on the $\mathrm{CD}$, credited to The Beatles.

"Sweet Georgia Brown" was written by Ben Bernie, Kenneth Casey and Maceo Pinkard, and published by Remick Music Corp., U. S. A. in 1925. The sheet music is reproduced in full in There Goes That Song Again by Colin Walsh (pp. 92-95). The original song, which is in the key of $\mathrm{G}$ major, includes a twenty-bar vocal introduction before the chorus. On Version A and Version B of the Polydor recordings this

[ ${ }^{*}$ Guzek (p. 2) credits the piano playing on the recordings to John Lennon, but, as we have seen in the discussion on Sutcliffe's involvement, Guzek's information on these sessions is not entirely reliable.]

$\left[{ }^{*}\right.$ The Swedish EP (Polydor 2230114 ) was available only by mail-order in a severely limited number. Our attempts to acquire a copy of this record have been unsuccessful.] 
introduction is omitted and the song consists of the chorus repeated twice with an instrumental break in between. The melody of the thirty-two bar chorus consists of four different phrases, of which the first is modulated twice in the first and once in the second half of the melody. The illustration below gives the form of the melody and its accompanying chord progression:

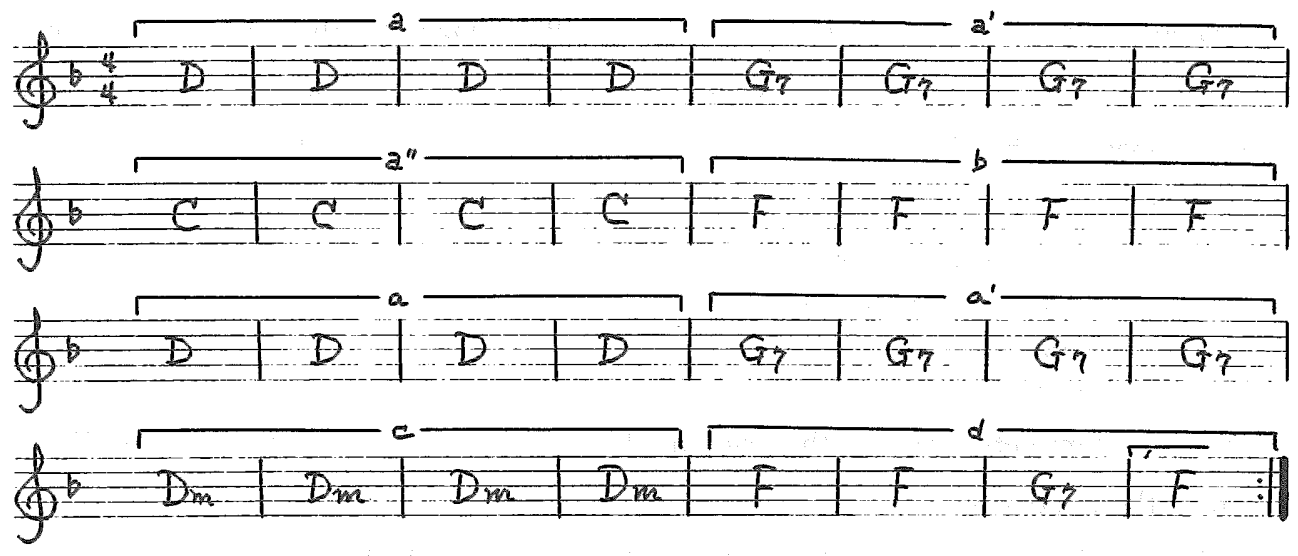

(As a matter of minor interest it should be noted that in both the recordings under discussion the melody in the first eight bars of the second chorus is a variation of the original one.)

An examination of the internal evidence of the recordings themselves reveals that Version $B$ differs from Version $A$ in a number of respects.

Firstly, Version B (like Version A') features the "original" lyrics with no reference to Liverpool, the Beatles, their hair or their fans.

Secondly, the two differ in length. Version $A$ is 2 minutes and 3 seconds long; Version B is 2 minutes and 28 seconds long. If Version B were the same as Version $\mathrm{A}^{\prime}$, then either some 25 seconds of the musical backing would have had to be edited out at the time the vocal track was rerecorded, or the tape must have been speeded up by some 17 per cent to produce Version A $\left({ }^{*}\right)$. If the tape speed had been accelerated, then the musical pitch would have been raised causing the song to move to a higher

[ ${ }^{*}$ Castleman \& Podrazik (A, p. 12) give the time for Version $\mathrm{A}^{\prime}$ as $2: 03$. However, in their second volume (B, p. 132) they admit that they do not possess a copy of the $Y a-Y a$ EP on which Version $\mathrm{A}^{\prime}$ appears. If follows that they assumed from the history of the recording that Version $A^{\prime}$ must be of the same length as Version A. The first two volumes of their discography were published in 1976 and 1977 respectively, so the Swedish reissue would not have been available to them. In the third volume (Castleman \& Podrazik-C, pp. 194 and 248) they discuss the Swedish EP, but give no indication of the length of "Sweet Georgia Brown".] 
key, i.e. from $F$ major to somewhere around $G$ sharp. In fact both versions are in the key of $\mathrm{F}$ major. The instrumental break in Version $\mathrm{A}$ is of sixteen bars duration whereas in Version B it is thirty-two bars long, i.e. the whole chorus. This accounts for the difference in length. However, close examination of Version A reveals no audible evidence that the tape has been spliced.

This evidence alone would rule out the possibility of Version $B$ being the same as Version $A^{\prime}$. However, as we shall see, the evidence examined to determine the answers to the second and third questions also reinforces this conlusion.

Version A includes two-part backing vocals which, it seems reasonable to suppose, were sung by The Beatles at the same time as the instrumental track was recorded and not at the time when the lead vocal was redubbed. If these backing vocals had not been present on the original recording, their overdubbing in 1963 would only serve to diminish the clarity of The Beatles' instrumental backing, the main selling-point of the recording. Version $B$ contains no backing vocals.

In terms of the instruments employed, Version A differs markedly from Version B. On Version A the instruments are an electric guitar, piano, drums plus a bass part which, almost alone among The Beatles' recordings, is played on an upright acoustic bass. On Version B the instrumentation is an electric guitar, piano, and drums plus an electric, fretted bass guitar and tenor saxophone. None of the other recordings credited to The Beatles contains a saxophone part and none of The Beatles themselves, with the possible exception of McCartney, was capable of playing the instrument at that time.

Moreover, as we have seen above, the instrumental break in Version A is sixteen bars shorter than that in Version $B$.

In general, on Version $\mathrm{A}$ the musicians are content to function simply as a rhythm section behind the vocal, with the piano providing minor embellishments. The instrumental arrangement on Version $B$, although in essence much the same as that on Version A, is more decorative and dynamically varied. For example, on Version A the guitar, bass and drums enter together on the first word of the first bar, after a sixsyllable anacrusis of unaccompanied vocal ("Well, let me tell you, well"), with the bass and drums playing a basic rhythm of :

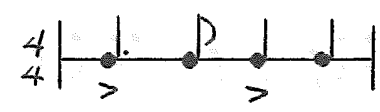


occasionally varied by :

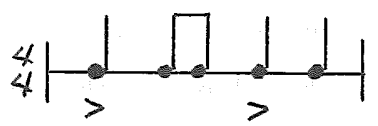

On Version B, on the other hand, a different six-syllable anacrusis ("I'll tell you something, well") is joined only by an underpinning bass and cymbal on the first bar, playing a basic rhythm pattern of :

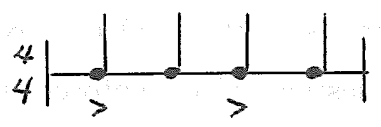

from the first beat of the first bar and for the following fourteen bars, before the piano and the rest of the drum kit come in. The guitar and tenor saxophone enter the arrangement unobtrusively about eleven bars later. The guitarist then strums a syncopated beat throughout, except for a flourish during the instrumental break, until the second chorus when he begins to decorate the vocal line with a repeated modulated ostinato, in the case of $\mathrm{F}$ thus:

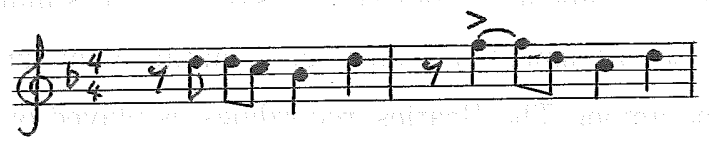

(The second bar is heavily accented and played note for note whereas the musicians sometimes vary the first, unaccented bar.)

The saxophonist's modest role is to play in subordinate unison with this ostinato, which incidentally is not indicated in the original 1925 sheet music. The pianist, meanwhile, supports the ostinato with rhythmic chords.

On Version A the guitarist continues to strum the syncopated beat throughout the song, again with the exception of the same brief flourish during the instrumental break, until the beginning of the final bar of the second chorus, when he plays the ostinato for four bars in unison with the pianist before the coda, which is suddenly slowed down to half speed, reminiscent of the bluesy song endings of Elvis Presley, for example in "I Got A Woman". An almost identical ostinato and coda also appear on the closing bars of Version $B$, which can be transcribed as:








The most clearly audible difference between the two versions is the piano part. Both are played in the boogie-woogie style which was popularized in rock'n' roll music by Jerry Lee Lewis among others, but a comparison of the two versions reveals a wide discrepancy in the skill of the pianists.

The difference is most conspicuous during the instrumental break. As we have already seen, on Version $A$ the instrumental break lasts for the customary sixteen bars whereas on Version $B$ the pianist is given the whole thirty-two bars of the chorus on which to display his virtuosity. On Version A the pianist seems to exhaust his invention within the sixteen bars and there is nothing about his playing to suggest that had he had the full thirty-two bars he would have produced anything exceptional. Clearly Sheridan's spoken comments over the piano break ("I say, this group is absolutely marvellous with the piano, don't you think so? ... Not too commercial, boys, not too commercial") are intended ironically, to judge by the upper-middle class accent he chooses to affect. The strident guitar on the four bars in D minor during the break provides an otherwise missing element of dynamic variation:

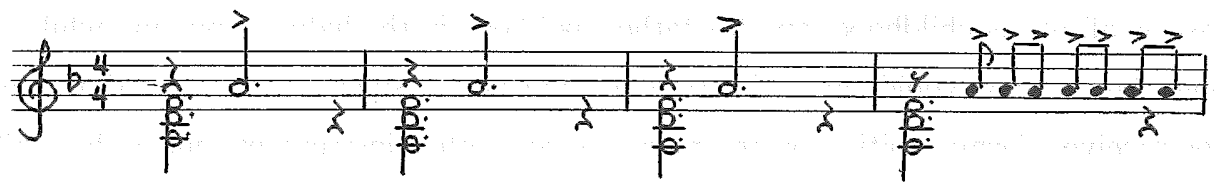

(Note: The chord on the first beat of each bar is played on the piano. On the second, third and fourth beats of the first three bars, none of the instruments sounds out the quadruple rhythm.)

This same guitar part is employed on the instrumental break of Version $B$, and it is this common factor, as much as any other, that might lead the unwary listener to suppose that both recordings were made by the same group.

On Version B the pianist clearly relishes the opportunity to extend his invention and the playing does not flag. The technique is fluid and exciting as the pianist maintains the rhythm with left-handed chords while adding lively and skillful decoration with his right hand. This contrasts with the flashy but crude hammering of the pianist on Version A, who alternates between maintaining the multiplicative rhythmic 
pattern:

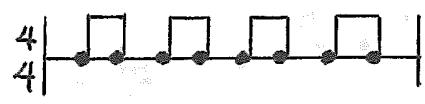

and a little vigorous but conventional improvisation, the whole burnished by one or two diatonic sweeps along the keyboard. So stark is the difference between the two that it is impossible to believe that they are one and the same person. A pianist with the skill which is displayed on Version B could not be content to confine himself to the limits which are clearly apparent in the playing of the pianist on Version A. On Version $B$ the piano, entering on the sixteenth bar, dominates the arrangement throughout whereas on Version A the piano does not enter until the instrumental break.

We conclude, therefore, that the musicians employed on the two recordings are different groups. The question remaining concerns which recording is by The Beatles. To determine this we first have to assess how well Paul McCartney, who is assumed to have played the piano on The Beatles' version of the song, could play the piano in 1961.

According to Welch (p. 18), Paul McCartney's first instrument was the trumpet-a birthday present from his father. His father, James McCartney, had been a semiprofessional musician and played the trumpet and piano $\left({ }^{*}\right)$. Although the guitar quickly became McCartney's abiding passion, there had been a piano in the house for most or all of his childhood, and his father had been in the habit of playing while the young McCartney would sing. There is no evidence to suggest that Paul McCartney ever received formal tuition on the piano (or any other instrument) during his childhood.

He presumably picked up some ability as a pianist, since in 1961 he sometimes played the piano at the Top Ten Club (Best and Doncaster, p. 103 ; Tamarkin). Martin (p. 138) notes that McCartney started taking piano lessons soon after The Beatles got together with Martin, i.e. no earlier than the latter part of 1962. Martin also describes McCartney's piano playing at the time of writing his book (1979) as "competent"

\footnotetext{
[*A piano which was sold by McCartney's father in 1955, when Paul McCartney was 12 or 13 years old, was sold at auction of 22nd December 1981 by Sotheby Parke Bernet \& Co., London. A photograph appears on p. 266 of Fenick. It fetched $£ 9,900$. Mr. McCartney apparently bought another to replace it since Welch says that $\mathrm{Mr}$. McCartney gave his son a guitar at sometime after the death of Mrs. McCartney, which occurred in 1956, and that Mr. McCartney showed his son some chords "at the piano" (Welch, p. 18).]
} 
(Martin, p. 139).

We can assume therefore that in $1961 \mathrm{McC}$ artney was capable of playing the piano well enough to appear with a beat group, but had had no formal training and had learned to play "by ear". This is consistent with the idea that McCartney played the somewhat crude piano part on Version A.

This conclusion, that Version A is played by The Beatles and therefore was recorded in mid-1961, is further reinforced by an examination of the other song recorded at the second session, on June 24th, namely, "If You Love Me, Baby". What is significant about these two recordings is that they both feature an upright bass, rather than an electric bass guitar. The difference between the two instruments is clearly audible, even though the musical range is the same. An upright bass has gut strings while an electric bass has steel strings; the types of string produce quite different sounds. Moreover, the fingering of the player plucking gut strings can be discerned, but this is not the case with steel strings. Finally, the upright bass has no frets on the fingerboard whereas ordinary electric bass guitars, such as the one on version $B$, do; with a fretted fingerboard it is not possible to produce the kind of slurring which can be heard on the first beat of the bar immediately after the guitar flourish, described above, during the instrumental break in Version A.

The recordings made at the earlier session feature a fretted electric bass guitar. However, apart from the piano, the instrumentation on "If You Love Me, Baby" is the same as that on "Sweet Georgia Brown", and these are the only songs to feature an upright bass. This fact obviously ties the recording of Version A to the same session as the recording of "If You Love Me, Baby", and, as we saw earlier, this is consistent with Best's account of the sessions.

Since there is nothing to suggest that Paul McCartney could play the upright bass with any degree of skill-indeed, no account indicates that he had ever tried-it seems reasonable to suppose that a studio musician was employed for this second session. This, of course, would free McCartney to play the piano on "Sweet Georgia Brown".

So, is it possible that Version B was recorded on December 21st and that the CD sleeve notes refer to this recording? As has been mentioned, another song is credited to that date on the CD sleeve, namely "Ready Teddy". If an obvious similarity exists between Version B and "Ready Teddy," then it can be supposed that this is indeed the case.

The instrumentation on the two songs is identical: an electric guitar, piano, 
electric bass, drums and tenor sexophone. The sound quality of each of these instruments is the same on both songs, although the arrangement on "Ready Teddy" is such that the guitar and piano are required only to sustain the vigorous syncopated rhythm and the musicians have little chance to display their individual skills. On "Ready Teddy" the saxophone is the featured instrument, unlike on "Sweet Georgia Brown", in which the instrument is given an entirely subsidiary, one could say superfluous, role. Since the saxophone plays no useful part in the recording of "Sweet Georgia Brown", one is tempted to conclude that its inclusion owes more to the incidental presence of a saxophonist, who seems to have been hired particularly for the recording of "Ready Teddy", than to any urgent musical consideration. These facts lead us to conclude that Version B of "Sweet Georgia Brown" was indeed recorded at the same session (December 21st) and with the same musicians as "Ready Teddy".

If further evidence were needed to suggest that the two recordings of "Sweet Georgia Brown" were made at some time apart, one can point to the contrasting degree of sophistication in the arrangements of the versions. Version B is clearly more carefully developed than Version A, and this apparent evolution of the song argues strongly in favour of Version B's having been recorded later than the musical accompaniment to Version A. This development in Sheridan's music is also evidenced in the contrast between the vocal styling of Version B, recorded in 1961, and the redubbed vocal on Version A, recorded some eighteen months later. His handling of the song in 1963 is considerably more self-assured and he betrays a familiarity with the song which allows him to take some licence with the phrasing. In contrast, the singing on Version B is somewhat stilted and conforms closely to the phrasing naturally suggested by the melody.

We believe that Version B has not been released anywhere but in Japan and West Germany $\left({ }^{*}\right)$, and that this occurred as a result of a mistake at Polydor Records, either in West Germany or Japan. Clearly someone at Polydor K.K. Japan should have spotted the error before the song was released to the public credited erroneously to The Beatles. However, but for this happy accident, we should not have been able to

[ ${ }^{*}$ A letter to Record Collector published in Issue 45, May 1983, reveals that, in addition to Version $A$ and Version A' of "Sweet Georgia Brown", two more versions of the song were issued in West Germany, both credited to Tony Sheridan and The Beat Brothers, one on the LP, My Bonnie (Polydor 46-612), and the other on the LP, Just A Litile Bit Of Tony Sheridan (Polydor 46-429), though which of these corresponds to our Version B is impossible to say. These records, which date from the very early 1960 's, are virtually impossible to find today.] 
conduct our research, the results of which are the following conclusions :

The recording sheet information conveyed on the sleeve of the $\mathrm{CD}$ concerning "Sweet Georgia Brown" is accurate insofar as it refers to Version B rather than Version A. It is, therefore, also credible when it comes to the information concerning the other songs recorded by The Beatles for Polydor Records, since there exist no other versions of these songs to cause similar confusion. From this and the other evidence, both external and internal, we conclude that at the time of recording the lineup of The Beatles comprised John Lennon (rhythm guitar), George Harrison (lead guitar), Paul McCartney (bass guitar and piano), and Pete Best (drums); that two tracks ("Ain't She Sweet" and "Cry For A Shadow") were recorded by The Beatles and four tracks ("My Bonnie", "The Saints", "Why" and "Nobody's Child") by The Beatles with Tony Sheridan at the Friedrich Ebert Halle, Hamburg-Harburg on 22nd and 23rd June, 1961 ; and that two more tracks ("Sweet Georgia Brown" and "If You Love Me, Baby") were recorded by The Beatles with Sheridan, and augmented by an upright bass player, at the Studio Rahlstedt on 24th June, 1961.

Appendix

"Sweet Georgia Brown : A 'Charleston-Swing' Song”

She just got here yesterday

Things are hot here now they say

There's a big change in town

Gals are jealous there's no doubt

Still the fellows rave about

Sweet, Sweet Georgia Brown

And ever since she came

The color'd folks all claim

Say, no gal made has got the shade

On Sweet Georgia Brown

Two left feet but oh! so neat has

Sweet Georgia Brown

They all sigh and wanna die

For Sweet Georgia Brown

I'll tell you just why 
You knòw I don' lie

[Spoken] Not much.

It's been said she knocks 'em dead when she lands in town

Since she came why it's a shame how she cools 'em down

Fellers she can't get are fellers she ain't met

Georgia claimed her

Georgia named her

Sweet Georgia Brown

Brown-skin gals you'll get the blues

Brown-skin pals you'll surely lose

And there's but one excuse

Now I've told you who she was

And I've told you what she does

Hand this gal her dues

This color'd maiden's pray'r

Is answered anywhere

Say, no gal made has got the shade

On Sweet Georgia Brown

Two left feet but oh! so neat has

Sweet Georgia Brown

They all sigh and wanna die

For Sweet Georgia Brown

I'll tell you just why

You know I don't lie

[Spoken] Not much

All those tips the porter slips to Sweet Georgia Brown

They buy clothes at fashion shows with one dollar down

Oh! Boy tip your hats

Oh! joy she's the "cats"

Who's that Mister

'Tain't her sister

Sweet Georgia Brown

Version A :

Well, let me tell you, well

No chick made could be the same

As Sweet Georgia Brown

Crazy feet that dance so neat

Has Sweet Georgia Brown

Fellers sigh and even cry 
For Sweet Georgia Brown

I'll tell you just why

You know I don't lie

Oh, it's been said she knocks 'em dead in any old town

Since she came, why, it's a shame how she brings 'em down

In Liverpool she even dared

To criticize The Beatles' hair

With their whole fan club standing there

I mean Sweet Georgia Brown

(Instrumental break)

[Spoken] I say this group is absolutely marvellous with the piano, don't you think so?

[Spoken] Not too commercial, boys, not too commercial.

Well, when it comes to music

Sweet Georgia knows her mind

Don't buy clothes at fashion shows

But she looks fine

Snap chicks cry, they want to die

When Georgia does the Twist

I never would try

To tell you just why

Use your imagination

There's a DJ crazy 'bout her living in our hometown

Since she came, why, it's a shame how she turned him down

Records that she can't get are records they ain't sent him yet

Carolina

May have Dinah,

But it don't have Georgia Brown

Well, I said, Sweet Georgia, yeah, yeah, yeah, and I mean

Brown, whoa, Sweet Georgia Brown

Version B :

I'll tell you something, well

No gal made has whoa-a got the shade

On Sweet Georgia Brown

She got two left feet, but, oh! so neat

Has Sweet Georgia Brown

They all sigh, oh, they wanna die

For Sweet Georgia Brown

I'll tell you just why 
You know I don't lie

Not much

Whoa, It's been said she knocks 'em dead when she lands in town

Since she came, why, it's a shame how she cools 'em down

Fellers, mm, she can't get are fellers, ooh, she ain't met

Georgia claimed her

Georgia named her

Sweet Georgia Brown

(Instrumental break)

Well, all those tips the porter slips

To Sweet Georgia Brown

She buys clothes at fashion shows

With one dollar down

They all sigh, yeah, they wanna die

For Sweet Georgia Brown

I'll tell you just why

You know I don't lie

Whoa, it's been said she knocks 'em dead when she lands in town

Since she came, why, it's a shame how she cools 'em down

Fellers she can't get, whoa, are fellers she ain't met

Georgia claimed her

Georgia named her

Sweet Georgia Brown

Whoa, I said, Sweet Georgia, whoa, whoa, whoa, Brown,

Oh yeah

\section{Bibliography}

Best and Doncaster

Brown and Gaines

Castleman \& Podrazik-A

Castleman \& Podrazik-B

Castleman \& Podrazik-C

Davies
Best, Pete and Doncaster, Patrick : Beatle! The Pete Best Story (London, 1985).

Brown, Peter and Gaines, Steven: The Love You Make: An Insider's Story of The Beatles (New York, 1983).

Castleman, Harry and Podrazik, Walter J. : All Together Now (Ann Arbor, Michigan, 1976).

Castleman, Harry and Podrazik, Walter J.: The Beatles Again? (Ann Arbor, Michigan, 1977).

Castleman, Harry and Podrazik, Walter J.: The End of The Beatles? (Ann Arbor, Michigan, 1985).

Davies, Hunter: The Beatles: The Biography, Revised Edition (New York, 1978). 
Doggett

Fenick

Gambaccini

Guzek

Harry

Lawrenson

Martin

Miles

Norman

O'Grady-A

O'Grady-B

Reinhart

Russell

Schaffner

Schultheiss

Speridan

Sheridan

Tamarkin

Taylor

Tremlett

Vollmer

Walsh

Welch

Williams and Marshall
Doggett, Peter : "The Beatles in Hamburg" in Record Collector, No. 41, January 1983.

Fenick, Barbara: Collecting The Beatles: An Introduction \& Price Guide To Fab Four Collectibles, Records \& Memorabilia (Ann Arbor, Michigan, 1982).

Gambaccini, Paul (ed.) : Paul McCartney In His Own Words (London, 1976).

Guzek, Arno:Beatles Discography (privately published, Hvidovre, Denmark, 1976).

Harry, Bill : The Beatles Who's Who (London, 1982).

Lawrenson, David: The Complete Guitar Guide (London, 1982). Martin, George with Hornsby, Jeremy : All You Need Is Ears (London, 1979).

Miles (ed.): The Beatles In Their Own Words (London, 1978). Norman, Philip: Shout! The True Story Of The Beatles (London, 1981).

O'Grady, Terence: "The Music of The Beatles from 1962 to Sergeant Pepper's Lonely Hearts Club Band", unpublished Ph. D. dissertation in Music, University of Wisconsin-Madison, 1975 .

O'Grady, Terence: The Beatles: A Musical Evolution (Boston, 1983).

Reinhart, Charles: The Book Of Beatles Lists (Chicago, 1985). Russell, Jeff: The Beatles Album File And Complete Discography (Poole, Dorset, 1982).

Schaffner, Nicholas: The Beatles Forever (Harrisburg, Pa., 1977).

Schultheiss, Tom (comp.): The Beatles: A Day In The Life: The Day-By-Day Diary 1960-1970 (New York, 1981).

Sheridan, Tony: Sleeve notes to The Beatles 1961 (Polydor MPF-1024)).

Stannard, Neville: The Long And Winding Road: A History Of The Beatles On Record (London, 1982).

Tamarkin, Jeff: "Pete. Best-A Beatle Talks", interview in Goldmine, No. 77, October 1982.

Taylor, Derek : Fifty Years Adrift (Guildford, Surrey, 1984).

Tremlett, George: The John Lennon Story (London, 1976).

Vollmer, Jurgen (photography) : Rock'n'Roll Times (New York, 1981).

Walsh, Colin (comp.): There Goes That Song Again: One Hundred Years Of Popular Song (London, 1977).

Welch, Chris : Paul McCartney: The Definitive Biography (London, 1984).

Williams, Allan and Marshall, William: The Man Who Gave The Beatles Away (New York, 1975).

28th April, $1986\left(^{*}\right)$

[* Since this article was submitted, our attention has been drawn to the latest edition of Hunter 
Davies' The Beatles (Jonathan Cape, London), published on 5th December, 1985. In the course of researching the introduction to this latest edition, Davies rediscovered among the material which he originally gathered for the book, a copy of the translation of the contract between The Beatles and Bert Kaempfert Produktion concerning the Polydor recording sessions, and this is reproduced in the book. In the contract The Beatles are listed as "John W. Lennon, James Paul McCartney, George Harrison, and Peter Best as Group called The Beatles". The contract is dated 12th May, 1961. Clearly, either Sutcliffe had already left the group by this date, or Kaempfert, at least, had decided that his playing was inadequate for a recording session. This further confirms our findings. The May date on the contract might explain the commonly-held belief that the recording sessions took place in May. However, there is no reason to suppose that the date on a contract is necessarily an indication of the date of fulfillment of that contract.

By a curious coincidence, Teichiku Records released an LP called The Savage Young Beatles (Overseas Records UPS-9001-V) on 1st July, 1986, which includes as a free gift a single (Beetlesong Records JPGR-5), coupling "Sweet Georgia Brown (Original Version)" with "Sweet Georgia Brown (Remix Version)". The "Remix Version" is, as one would expect, our Version A ; but the "Original Version" is billed on the "obi" as "said to be presently unavailable elsewhere in the world". The notes included with the LP go on to explain that this "Original Version" was recorded "at Tony Sheridan's first recording session with The Beatles, and was only released on the LP, My Bonnie, and the single [sic], "Ya-Ya", so this is an ultra-valuable take." It seemed that after nearly twentyfive years the general public would have access to the Ur-version of "Sweet Georgia Brown". To our disappointment and, no doubt, to the considerable embarrassment of Teichiku Records, this "Original Version" turns out to be our Version B, and therefore is not by The Beatles. One can only wonder at the carelessness of the record company in allowing such an obvious, albeit inadvertent, deception to be played on the general public. 